Original Research

\title{
A cross-sectional study of applied bioethical reasoning in pharmacy students and preceptors
}

\author{
Received (first version): $20-$ Dec-2013 Accepted: 1-Jun-2014
}

\begin{abstract}
*
Objective: To compare ethical principles most often utilized by pharmacy students and preceptors to determine plan of action for an ethical dilemma and to determine if ethical principles utilized are the same for individuals in the postconventional range

Method: A two part survey was administered to a convenience sample of pharmacy students and preceptors. The first part was comprised of an original measure, the Pharmacy Ethical Dilemmas Survey (PEDS), that was developed to assess participants' action choices on healthcare-related ethical dilemmas and which moral rule or ethical principle was most influential in their decision. The second part was comprised of the Defining Issues Test.

Results: Patient autonomy and non-maleficience were the primary bioethical principles applied by students but pharmacists applied non-maleficience, patient autonomy, and also pharmacist autonomy. For all scenarios, students were more likely to rely on the principle of beneficence, while preceptors were more likely to rely on the pharmacist's right to autonomy. In the analysis of application of bioethical principles by higher and lower principled reasoning individuals, only in the assisted suicide scenario did the two groups agree on the primary principle applied with both groups relying predominantly on patient autonomy.

Conclusion: Students and preceptors utilize different bioethical principles to support how they would handle each ethical dilemma but $P$-scores do not play a role in determining which bioethical principles were used to justify their action choices.
\end{abstract}

Keywords: Ethics, Pharmacy; Principle-Based Ethics; Professional Practice; Attitude of Health Personnel; United States

"Lauren S. SCHLESSELMAN. MA Ed Psych, PharmD. Associate Clinical Professor and Director of Assessment and Accreditation, School of Pharmacy, University of Connecticut. Storrs, CT (United States).

\section{INTRODUCTION}

In any pharmacy setting, pharmacists face ethical dilemmas on a daily basis. As the pharmacist's responsibilities expand, they will soon be faced with dilemmas seen by other healthcare professionals working in clinical settings, leading to higher levels of moral distress. ${ }^{1}$ To handle these newer dilemmas and higher levels of distress, pharmacists rely not only on their own moral values but also on ethical rules and principles established by the profession. The pharmacist may face situations in which their own moral values are in conflict with ethical principles established by the profession or in which multiple ethical principles may be applicable, resulting in an ethical dilemma.

These authentic dilemmas faced by pharmacists are complex cognitive and emotional experiences, wherein deeply-held moral and/or ethical values or principles are pitted against one another. A decision must be rendered and no one solution is clearly right or wrong. Thus, the pharmacist must weigh and prioritize numerous moral or ethical options when making a decision. This moral reasoning, upon which life and death decisions in part depend, is a critical component in the moral functioning of pharmacy students and professionals. ${ }^{2,3}$

Learning to deal with ethical dilemmas starts with understanding the ethical principles established by the pharmacy profession. This understanding of ethical principles requires exposure to ethical dilemmas early in their training, preferably as pharmacy students. To increase moral development, particularly moral reasoning (i.e. the ability to perceive and consider two or more competing moral values or principles in making a moral judgment), during their training, pharmacy schools strive to expose students to ethical dilemmas. Many pharmacy schools include a pharmacy ethics course, often in conjunction with a pharmacy law course, in their curriculum. Outside of these courses, students are also exposed to ethical dilemmas during introductory and advanced pharmacy practice experiences. The goals of this education in ethics are to expand student awareness of ethical dilemmas faced by pharmacists and to develop skills for handling ethical dilemmas. In the language of cognitivestructuralist theories of moral development, the goal of these courses and experiences is to encourage progression to the next stage of moral reasoning: pre-conventional thinking (rooted in ego-centric concerns of harm and benefit) to post-conventional or principled reasoning (rooted in concerns for universal justice and fairness). ${ }^{2,4,5}$ 
With the advancement of the pharmacists' role in medication therapy management and pharmacotherapy decision making, a well-rounded pharmacy education must also ensure that graduates are prepared for the moral and ethical challenges they will face. Unfortunately, previous studies into the moral development of pharmacists, in particular community pharmacists, have found they have low moral development, as measured by the Defining Issues Test ${ }^{\circledR}$ (DIT) developed by Rest and colleagues. In these studies, community pharmacists were found to have lower DIT P\% scores than other practicing health care providers. ${ }^{6,7}$ This study seeks to examine pharmacy students' moral development by identifying which ethical principles they utilize in handling these dilemmas. Secondarily, the study aims to evaluate the relationships between moral rule or ethical principle utilized and the level of moral development.

\section{Bioethical principles}

Ethics represent a codified set of standards of behavior adopted by a group of people. For pharmacists this set of ethics is outlined in the American Pharmacists Association's Code of Ethics. The Pharmacist's Code of Ethics is based on the primary principles of bioethics: autonomy, beneficence, non-maleficence, and justice, veracity, fidelity, and confidentiality. ${ }^{8}$ Although these principles represent the values of the profession, providing a framework and guidance, they are not absolutes and do not give answers as to how to handle the many variables associated with each clinical situation. Instead the ultimate choice lies with the pharmacist. So, how will a pharmacist decide which path to take when faced with an ethical dilemma?

The first principle, autonomy, represents an individual's right to refuse or choose a course of action. The meaning has evolved to roughly mean "being one's own person," including "personal rule of the self while remaining free from both controlling interferences by other and personal limitations". 8 In healthcare, autonomy is heavily grounded in the patient's right to consent to or to refuse treatment. In some instances, the patient's ability to consent is questioned due to their lack of competence. Physical and mental competencies are preconditions for being able to act autonomously, often leaving healthcare providers with the challenge of determining competence.

Although often forgotten, autonomy also encompasses the pharmacist's rights. This may take the form of the pharmacist choosing to adhere to the law, rather than to "bend" the law to better serve the patient. The pharmacist may also exert autonomy by selecting to put the patient's rights before the regulations governing pharmacy practice.

Beneficence encourages the pharmacist to act in the best interest of the patient. Not only should the pharmacist not inflict harm, he should prevent and remove harm while promoting good. Beneficence involves performing positive acts, including, but not limited to, mercy, kindness, and charity, rather than the absence of negative acts. In healthcare, beneficence often requires a weighing of risks versus benefits. The third principle, nonmaleficence, is based on the notion of Primum non nocere ("first, do no harm"). In some cases, the distinction between nonmaleficence and beneficence may seem difficult to discern due to the need to balance these two principles. In cases where the patient's quality of life plays a critical role, such as end of life concerns, weighing nonmaleficence and beneficence takes front stage.

Justice relates to fairness and equality. In healthcare this especially concerns distributive justice when scarcity of and competition for resources exist. When faced with a situation in which health resources are scarce, the healthcare provider must consider who receives treatment. In particular, justice concerns arise in the rationing of healthcare based on ability to pay for care.

Although autonomy, beneficence, nonmaleficence, and justice represent the four primary bioethical principles, veracity, confidentiality, and fidelity are principles essential to the pharmacist-patient relationship. Veracity involves an obligation to tell the patient the truth and not deceive them. This principle relates to the patient's need for complete information in order to provide informed consent, to the pharmacist's promise to not mislead, and the need for healthy relationship between pharmacists and patients. In the past few years, the Health Insurance Portability and Accountability Act (HIPAA) (P.L.104-191) has reinforced the importance of confidentiality, requiring healthcare professionals and institutions to further protect patient health information. The final principle, fidelity, from the Latin root "fides" which mean faithfulness, addresses the unspoken covenant between pharmacists and patients and promise keeping.

Although studies are available to evaluate how pharmacists and pharmacy students handle ethical dilemmas $^{9-12}$, no studies are available which compare pharmacy students versus pharmacists in their selection of bioethical principles to deal with ethical dilemmas. Available studies only look at pharmacist application of bioethical principles but reported that pharmacists relied most heavily on respect for medicines and doing what was in the patient's best interest when dealing with ethical dilemmas. ${ }^{13}$ In the study by Hibbert and colleagues, community pharmacists report routinely dealing with ethical dilemmas including situations pertaining to autonomy of the patient and pharmacy personnel, beneficence, and nonmaleficence. ${ }^{14}$ When faced with a dilemma which required choosing between ethical principles and legal requirements, the pharmacists opted to comply with the Code of Ethics, rather than staying within the law. These results differ from those found by Lowenthal. ${ }^{15}$ Although he also noted a high degree of concern for the patient and the patient's rights, he found that this concern for the patient was maintained regardless of the economic or legal conflicts.

\section{Moral development}

Recently, a neo-Kohlbergian perspective was formulated by Rest et al. in response to data 
collected with their Defining Issues Test $\AA$ (DIT), an objective measure of morality. ${ }^{5}$ Corresponding to Kohlberg's three levels of moral reasoning, ${ }^{16}$ this neo-Kohlbergian theory identifies three schemas personal interests, maintaining norms, and postconventional schemas. In the personal interests schema, a sociocentric perspective is lacking, rather information is filtered based on personal interests.7 Interaction and cooperation with others is viewed, not at the societal level, but as if only micro-morality relationships exist. The shift to maintaining norms schema becomes apparent when awareness of macro-morality develops, taking into account the welfare of society. At this level the individual perceives the need for established practices and norms that govern society, along with the expectation that everyone recognizes their duty to obey these norms. The individual respects the authority of the system as most important. Finally, in the postconventional schema, moral obligations are based on shared ideals and values.

The primary objectives of the study were to evaluate the ethical decision making of pharmacy students during pharmacy school, in particular the application of principles of bioethics and to compare the application of bioethical principles by pharmacy students and preceptors. A secondary objective was to compare the application of bioethical principles with the level of moral development, as assessed by the Defining Issues Test. Specifically, these research questions were examined:

Research question 1: Which moral rules or ethical principles are most often utilized by students and pharmacists to determine a plan of action for an ethical dilemma?

Hypothesis 1: A statistically significant difference exists in ethical principles utilized by pharmacy students and pharmacists to determine a course of action for an ethical dilemma

Research question 2: Do pharmacy students and pharmacists with DIT scores in the postconventional range utilize different ethical principles when dealing with ethical dilemmas?

Hypothesis 2: Currently no studies are available pertaining to the relationship between the DIT results and application of ethical rules and principles. Due to the lack of previous studies, there is no theoretical grounds for formulating a hypothesis at this time therefore this will be an exploratory analysis.

\section{METHODS}

\section{Participants}

Participants for this study were selected through a convenience sample of pharmacy students enrolled at the University of Connecticut School of Pharmacy and preceptors for the school. The students were enrolled in the four professional years of the Doctor of Pharmacy program. To be included, the preceptor must have been either a full-time faculty member at a school or college of pharmacy, have completed a pharmacy residency program or fellowship, or served as a preceptor for at least 3 years.

\section{Measures}

For the purpose of this study, participants completed an online survey consisting of three parts.

The first part was comprised of an original measure, the Pharmacy Ethical Dilemmas Survey (PEDS), that was developed to assess participants' action choices on healthcare-related ethical dilemmas and which moral rule or ethical principle was most influential in their decision. The dilemmas related to sedating an unruly patient, use of placebo medication, assisted suicide, and use of expired medications on a mission trip. These hypothetical dilemmas require each participant to determine if he was willing to dispense the medication when faced with that dilemma and to identify the reason for his decision. Each of the reasons provided on the survey instrument related to one of the bioethical principles or moral rules (although they are not identified as such on the survey instrument). The second part of the survey used the Defining Issues Test (DIT-1® short form) to assess participants moral development. The DIT-1® short form consists of 3 scenarios for which the participant must rank the four most important of 12 statements in determining how to handle the scenario. The four statements selected as most important are given weighted scores. A raw principled morality score ( $P$ score) is obtained by adding up the weighted points. The raw score is converted to a percentage by dividing by 0.3 , providing scores ranging from 0 to 100. To check for reliability of results, the "M" score is checked. " $M$ " items are statements that were written to sound pretentious, rather than to imply a degree of moral development. The DIT developers determined that a tendency to select these "M" items as important represented the subject's tendency to endorse pretentious statements, rather than endorsing statements for their meaning. A high "M" score occurs when participants select the M statements as being the most important. If the participant achieves an "M" score of 4 or higher than the participant's DIT is considered invalid, because the DIT developers determined a high score brought into question the subject's test taking skills. Unlike the PEDS, the DIT does not ask the participant to state what decision he made, just to rank importance of issues. The final part of the survey asks participants to provide demographic and experiential information related to their education and/or career.

\section{Procedure and Data Analysis}

Following Institutional Review Board approval, students and preceptors were asked to complete the survey online via SurveyMonkey ${ }^{\circledR}$. Invitations and reminders to participate were sent using pharmacy school listservs. All students and pharmacists completed the assessment anonymously. For all measures, the p-value for statistical significance was set at the 0.05 level. For research question 1 , the "correct" reason, based on the bioethical principles, for opting to dispense or 


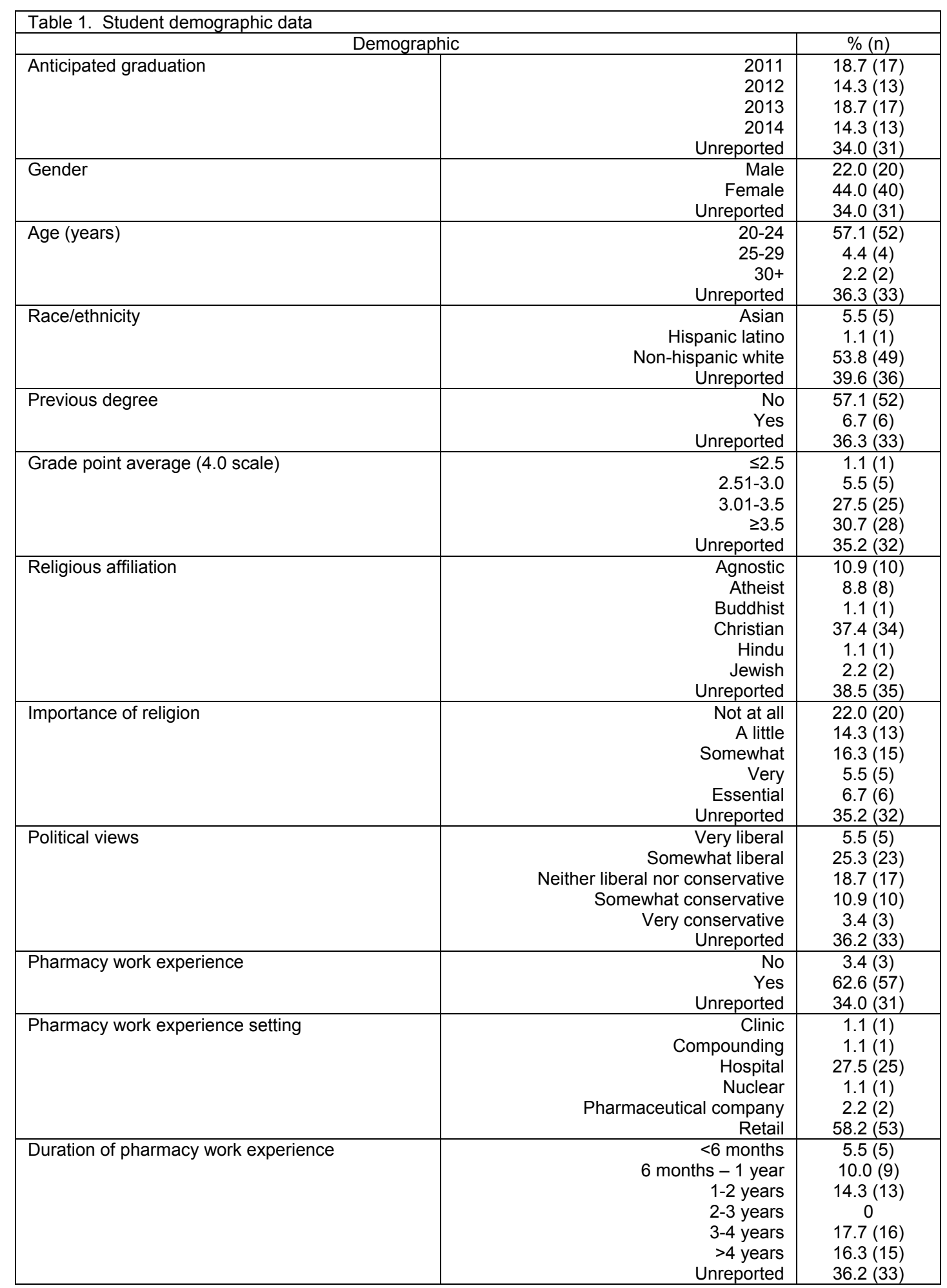

not dispense the medication is based on personal views and perspectives. As such, the first analysis was to evaluate the descriptive statistics pertaining to the frequency with which students and pharmacists utilize each of the bioethical principles to handle the pharmacy-specific moral dilemma. This was followed by Chi squared analysis. For any analyses with $n<5$ per cell, Fisher's exact test was utilized. For research question 2, DIT scores were considered in the lower extreme if they were between $0-24$, while scores were considered high if they were 45 or lower. Chi squared was utilized to determine if students and preceptors with DIT P\% scores in the extremes utilized the same or different bioethical principles.

\section{RESULTS}

Ninety-one pharmacy students and 45 preceptors participated in the study, although not all participants completed every portion of the survey. Of the 91 students, 31 only completed the PEDS portion of the survey, while skipping the DIT and demographics. For those students who completed 


\begin{tabular}{|c|c|c|}
\hline \multicolumn{2}{|c|}{ Demographic } & $\%(n)$ \\
\hline Gender & $\begin{array}{r}\text { Male } \\
\text { Female } \\
\text { Unreported }\end{array}$ & $\begin{array}{l}26.7(12) \\
28.9(13) \\
44.4(20)\end{array}$ \\
\hline Age (years) & $\begin{array}{r}<30 \\
30-39 \\
40-49 \\
50-59 \\
60-69 \\
70+ \\
\text { Unreported } \\
\end{array}$ & $\begin{array}{c}2.2(1) \\
26.7(12) \\
11.1(5) \\
8.9(4) \\
4.4(2) \\
2.2(1) \\
44.4(20) \\
\end{array}$ \\
\hline Race/ethnicity & $\begin{array}{r}\text { Asian } \\
\text { Hispanic latino } \\
\text { Non-hispanic white } \\
\text { Unreported } \\
\end{array}$ & $\begin{array}{c}4.4(2) \\
2.2(4) \\
49.0(22) \\
44.4(20) \\
\end{array}$ \\
\hline Religious affiliation & $\begin{array}{r}\text { Agnostic } \\
\text { Atheist } \\
\text { Christian } \\
\text { Hindu } \\
\text { Jewish } \\
\text { Unreported }\end{array}$ & $\begin{array}{c}4.4(2) \\
6.6(3) \\
37.9(17) \\
2.2(1) \\
2.2(1) \\
46.7(21) \\
\end{array}$ \\
\hline Importance of religion & $\begin{array}{r}\text { Not at all } \\
\text { A little } \\
\text { Somewhat } \\
\text { Very } \\
\text { Essential } \\
\text { Unreported }\end{array}$ & $\begin{array}{c}6.6(3) \\
4.4(2) \\
28.9(13) \\
13.3(6) \\
2.2(1) \\
44.4(20)\end{array}$ \\
\hline Political views & $\begin{array}{r}\text { Very liberal } \\
\text { Somewhat liberal } \\
\text { Neither liberal nor conservative } \\
\text { Somewhat conservative } \\
\text { Very conservative } \\
\text { Unreported }\end{array}$ & $\begin{array}{c}0 \\
17.8(8) \\
17.8(8) \\
15.6(7) \\
4.4(2) \\
44.4(20) \\
\end{array}$ \\
\hline Highest degree earned & $\begin{array}{r}\text { Bachelor } \\
\text { Master } \\
\text { PharmD } \\
\text { PhD } \\
\text { Unreported }\end{array}$ & $\begin{aligned} 24.5(11) \\
2.2(1) \\
26.7(12) \\
2.2(1) \\
44.4(20)\end{aligned}$ \\
\hline Pharmacy position & $\begin{array}{r}\text { Clinical pharmacist } \\
\text { Faculty } \\
\text { Pharmacy manager } \\
\text { Staff pharmacist } \\
\text { Unreported }\end{array}$ & $\begin{array}{c}17.8(8) \\
8.9(4) \\
15.6(7) \\
15.6(7) \\
42.2(19) \\
\end{array}$ \\
\hline Pharmacy setting & $\begin{array}{r}\text { Inpatient hospital } \\
\text { Outpatient clinic } \\
\text { Retail } \\
\end{array}$ & $\begin{array}{c}17.8(8) \\
4.4(2) \\
22.2(10) \\
\end{array}$ \\
\hline \# years as pharmacist & $\begin{array}{r}<5 \\
5-10 \\
11-20 \\
21-30 \\
30+ \\
\text { Unreported } \\
\end{array}$ & $\begin{array}{c}2.2(1) \\
13.3(6) \\
20.0(9) \\
11.1(5) \\
9.0(4) \\
44.4(20) \\
\end{array}$ \\
\hline \# years as preceptor & $\begin{array}{r}<5 \\
5-10 \\
11-20 \\
21-30 \\
\text { Unreported }\end{array}$ & $\begin{array}{c}22.2(10) \\
17.8(8) \\
13.3(6) \\
2.2(1) \\
44.4(20) \\
\end{array}$ \\
\hline
\end{tabular}

the DIT, the results from four students were found to be invalid due to M-scores 4 or higher. Of the 49 preceptors, 20 only completed the PEDS portion, while skipping the DIT and demographics. For those preceptors who completed the DIT, the results from two preceptors were found to be invalid due to elevated $\mathrm{M}$-scores.

\section{Demographics}

When looking at the demographic information provided by the students, the participant sample closely models the actual pharmacy school population (see Table 1). The majority of students are under the age of 25 years, consider themselves to be non-Hispanic White, and have no previous degree. As with the pharmacy student population, female participants outnumbered male at a ratio of 2 to 1 . More than $60 \%$ of students considered themselves Christian with nearly $20 \%$ considering religion very important or essential. Nearly $90 \%$ of student participants who provided demographic data report having a grade point average greater than 3.0. More than $95 \%$ reported having pharmacy-related work experience. While some students reported having multiple pharmacy-related positions, the most frequently reported position was in the retail pharmacy setting. Approximately half of the students reported three or more years of 


\begin{tabular}{|c|c|c|c|c|c|c|c|c|}
\hline \multirow[b]{2}{*}{ Bioethical principle } & \multicolumn{2}{|c|}{ Placebo medication } & \multicolumn{2}{|c|}{ Sedating unruly pt } & \multicolumn{2}{|c|}{ Assisted suicide } & \multicolumn{2}{|c|}{ Expired medications } \\
\hline & $\begin{array}{c}\text { Students } \\
n=60\end{array}$ & $\begin{array}{c}\text { Preceptors } \\
n=26\end{array}$ & Students & Preceptors & Students & Preceptors & Students & Preceptors \\
\hline Patient autonomy & $36 \%$ & $36.0 \%$ & $15.0 \%$ & $7.7 \%$ & $45.5 \%$ & $32.0 \%$ & $4.6 \%$ & $8.0 \%$ \\
\hline Pharmacist autonomy & $3.3 \%$ & $20.0 \%$ & $11.2 \%$ & $34.6 \%$ & $7.9 \%$ & $16.0 \%$ & $28.7 \%$ & $28.0 \%$ \\
\hline Non-maleficience & $21.1 \%$ & $20.0 \%$ & $31.3 \%$ & $26.9 \%$ & $30.7 \%$ & $44.0 \%$ & $33.3 \%$ & $44.0 \%$ \\
\hline Beneficence & $17.8 \%$ & $12.0 \%$ & $30.0 \%$ & $7.7 \%$ & $9.1 \%$ & $4.0 \%$ & $16.1 \%$ & $12.0 \%$ \\
\hline Veracity & $7.8 \%$ & $8.0 \%$ & $2.5 \%$ & $3.8 \%$ & $1.1 \%$ & $4.0 \%$ & $3.4 \%$ & $4.0 \%$ \\
\hline Justice & $3.3 \%$ & $0 \%$ & $5.0 \%$ & $11.5 \%$ & $2.3 \%$ & $0 \%$ & $10.3 \%$ & $4.0 \%$ \\
\hline Fidelity to doctor & $0 \%$ & $4.0 \%$ & $2.5 \%$ & $3.8 \%$ & $1.1 \%$ & $0 \%$ & $1.1 \%$ & $0 \%$ \\
\hline Pt-RPh relationship & $6.7 \%$ & $0 \%$ & $2.5 \%$ & $3.8 \%$ & $2.3 \%$ & $0 \%$ & $2.3 \%$ & $0 \%$ \\
\hline
\end{tabular}

pharmacy work experience with the other half reporting two or less years of experience.

As for the preceptors, participants who provided demographic data showed equal representation by both genders, along with being evenly divided between pharmacists under the age of 40 years and those who are 40 years and older (see Table 2). Slightly more than half of the preceptors who provided demographics reported holding a PharmD, Master, or PhD. Half of the pharmacists also reported working in the retail setting. Only four preceptors reported being faculty at the school with the remaining preceptors divided between staff pharmacists, clinical pharmacists, and pharmacy managers positions. All but one preceptor reported working as a pharmacist for at least 5 years with the majority reporting working as a pharmacist for more than 10 years. Sixty percent of preceptors reported serving as preceptors for 5 or more years. As with the student participants, the majority of preceptors consider themselves non-Hispanic White. Nearly $75 \%$ of preceptors considered themselves Christian but less than $5 \%$ considered religion very important or essential.

\section{Ethical dilemma application of bioethical principles}

Overall, patient autonomy and non-maleficience were the primary bioethical principles applied by students but pharmacists applied non-maleficience, patient autonomy, and also pharmacist autonomy. As detailed in Table 3, for all four scenarios, students were more likely to rely on the principle of beneficence, while preceptors were more likely to rely on the pharmacist's right to autonomy.

Students and preceptors utilized similar bioethical principles when handling placebo and expired medication scenarios. For the scenario involving use of placebo medication, patient autonomy was the primary principle utilized by both students and preceptors. For the expired medications on a mission trip, students and preceptors also utilized the same primary principle but for this scenario they relied on non-maleficience.

For the scenarios pertaining to sedation and assisted suicide, students and preceptors differed in the primary principles utilized. Students utilized non-maleficience as the primary principle for the sedation of an unruly patient, while pharmacists utilized the pharmacist's right to autonomy. For the assisted suicide, students utilized the patient's right to autonomy as primary reason for decision, but pharmacists relied on the principle of nonmaleficience.

\section{Moral development and bioethical principles}

In this analysis, participants with high DIT scores were compared with those with lower scores to determine if they utilized different bioethical principles. To conduct this analysis, two "extreme" groups were created using a tertile split, where the lower and higher ends are retained and the middle group eliminated. Twenty-two respondents had Pscores in the higher principled reasoning tertile, equivalent to P-score of 45.0 or higher. Of these 22 respondents, 6 were preceptors and 16 were students. Twenty-three respondents had P-scores in the lower principled reasoning tertile, equivalent to P-score of 24 or lower. Of these 23 respondents, 10 were preceptors and 13 were students. Chisquare analyses revealed no statistically significant under- or over-representation of respondents in these two extreme groups based on sex, professional status (i.e., student vs. preceptor), or political orientation (i.e., liberal, middle of the road, conservative). However, there was a statistically significant (chi-square $=5.88, \quad p>0.05$ ) underrepresentation of highly religious respondents in the high reasoning group. Specifically, there was only one respondent who indicated that religious was of "very" or "essential" importance to them in the group with highest $p$-scores (comprising only $4.5 \%$ of group membership). There were seven such

\begin{tabular}{|l|c|c|c|c|c|c|c|c|}
\hline Table 4. Impact of DIT P\% on bioethical principles utilized by students and pharmacists \\
\hline \multirow{2}{*}{ Bioethical principle } & \multicolumn{2}{|c|}{ Placebo medication } & \multicolumn{2}{c|}{ Sedating unruly pt } & \multicolumn{2}{c|}{ Assisted suicide } & \multicolumn{2}{c|}{ Expired medications } \\
\cline { 2 - 9 } & Low DIT (\%) & High DIT & Low DIT & High DIT & Low DIT & High DIT & Low DIT & High DIT \\
\hline Patient autonomy & $19.0 \%$ & $\mathbf{4 0 . 9 \%}$ & $5.0 \%$ & $4.5 \%$ & $\mathbf{4 0 . 0} \%$ & $\mathbf{5 4 . 5 \%}$ & $5.0 \%$ & $4.5 \%$ \\
\hline RPh autonomy & $14.3 \%$ & $9.1 \%$ & $15.0 \%$ & $27.3 \%$ & $25.0 \%$ & $0 \%$ & $\mathbf{4 5 . 0} \%$ & $18.2 \%$ \\
\hline Non-maleficience & $\mathbf{2 8 . 6 \%}$ & $18.2 \%$ & $\mathbf{4 5 . 0} \%$ & $22.7 \%$ & $25.0 \%$ & $27.3 \%$ & $35.0 \%$ & $\mathbf{3 1 . 8} \%$ \\
\hline Beneficence & $14.3 \%$ & $18.2 \%$ & $10.0 \%$ & $\mathbf{3 6 . 4} \%$ & $10.0 \%$ & $18.2 \%$ & $5.0 \%$ & $27.3 \%$ \\
\hline Veracity & $4.8 \%$ & $9.1 \%$ & $5.0 \%$ & $0 \%$ & $0 \%$ & $0 \%$ & $0 \%$ & $4.5 \%$ \\
\hline Justice & $0 \%$ & $0 \%$ & $5.0 \%$ & $4.5 \%$ & $0 \%$ & $0 \%$ & $10.0 \%$ & $13.6 \%$ \\
\hline Fidelity to doctor & $4.8 \%$ & $0 \%$ & $5.0 \%$ & $4.5 \%$ & $0 \%$ & $0 \%$ & $0 \%$ & $0 \%$ \\
\hline Pt-RPh relationship & $4.8 \%$ & $4.5 \%$ & $10.0 \%$ & $0 \%$ & $0 \%$ & $0 \%$ & $0 \%$ & $0 \%$ \\
\hline *bold font represents bioethical principle with highest frequency per sample group per scenario & & & \\
\hline
\end{tabular}


respondents in the low reasoning groups (comprising $33.3 \%$ of group membership).

In the analysis of application of bioethical principles by high and low principled reasoning groups, only in the assisted suicide scenario did the two groups agree on the primary principle applied with both groups relying predominantly on patient autonomy (Table 4). With the placebo medication scenario, respondents with low DIT scores relied on nonmaleficience while individuals with high scores relied on patient autonomy. Individuals with low DIT $\mathrm{P} \%$ also relied on non-maleficience when addressing the sedating unruly patient scenario. For this scenario, high DIT P\% individuals relied on beneficence. In the expired medication scenario, $45 \%$ of low principled reasoning respondents utilized the principle of pharmacist autonomy and $35 \%$ relied on non-maleficience, as did $31.8 \%$ of high principled reasoning respondents.

\section{DISCUSSION}

By analyzing the bioethical principles that students and preceptors applied when handling the ethical dilemmas, differences were noted between students' and preceptors' responses. Although in some instances these differences did not reach statistical significance, they may have practical significance. When considering bioethical principles, students relied on patient autonomy and non-maleficience, while pharmacists also considered pharmacist autonomy. This suggests that students made decisions focused on patient rights, either based on their own moral code or the ethics code of the profession. In contrast, pharmacists also added legally conservative considerations. This may be because they were not as focused on the patients' needs or because of their need to protect their pharmacist license. Interestingly, students relied on the pharmacist's right to autonomy when considering the use of expired medications. This would seem to suggest that the students felt they had the right to overrule FDA mandated expiration dates or federal law.

In the comparison of bioethical principles selected by participants with DIT scores at the extremes, the principles utilized when making decisions seem to align with the level of principled reasoning for some of the scenarios. For the scenario involving use of a placebo medication, the students and preceptors with higher principled reasoning predominantly utilized patient autonomy, while those with lower principled reasoning utilized non-maleficience. The use of patient autonomy would be in-line with the focus on society, rather than self, of the high principled reasoning individual. For the scenario involving the expired medication, the use of pharmacist autonomy by the low principled reasoning individuals represents the personal interest domain of the neo-Kohlbergian theory. This is of particular interest considering the significant representation of "highly religious" individuals in this group. Despite the importance of religion to these individuals, they utilized a personal interest domain, rather than considering the whole society. This aligns with their lower principled reasoning level, than with a "highly religious" viewpoint. In contrast, for the expired medication scenario, the high principled reasoning individuals utilized nonmaleficience, which would be in-line with a societal view of preventing harm to the whole society. Interestingly, for the assisted suicide scenario, both high and low principled reasoning was associated with use of the same principle, patient autonomy.

Schools and the pharmacy profession need to determine if students or pharmacists are working in the best interests of patients and the profession when handling ethically challenging situations. If the pharmacists' approach is considered the ideal, then schools need to expose students to more clinical experiences throughout their education to aid students in reaching that goal. Yet, the Pharmacist's Code of Ethics stresses covenantal relationship with patients and respecting patient autonomy and dignity, making it appear that student views may be more in line with the code. If so, the profession may need to determine how to remind pharmacists of their values as a pharmacy student. Developing a longitudinal study to follow pharmacy students throughout their pharmacy education and into their professional practice would be interesting in that it would determine when these changes occur.

A limitation of the study is the small participant numbers which may have hindered the ability to reach significance. In some analyses, it appears that the difference is significant but in actuality it does not reach it due to small cell sizes. Another limitation related to the pilot nature of this study is the influence on demographics. It is unknown if a broader study would have changed demographics, such as the importance of religion, and the impact that would have on the results.

With the design of this study, certain threats to validity existed. One such threat to validity is maturation. There was a possibility that the differences in outcomes may be attributed to the changes of students' internal states during their advancement through the professional program, possibly through internship or personal experiences outside of the curriculum, rather than through learning occurring in the curriculum.

A second threat to the validity was instrumentation. The first instrumentation threat is the possibility that students, particularly those early in their training, may not have been exposed to the moral dilemmas expressed in the cases. Due to lack of exposure, the students may not fully grasp the moral implications of the case. The second threat to instrumentation was the length of the survey. As demonstrated by the number of participants who opted to complete only the section on ethical dilemmas and to forego the DIT and demographics sections, the instrument required more time to complete than many students and preceptors were willing to give. The third threat to instrumentation was the use of the DIT-1 short form. Particularly in the case involving the school newspaper, the information presented in the case was outdated. In particular, many students are too young to remember the Vietnam War, to remember when 
long hair on male students was an issue in schools, or to understand what mimeographing is.

Further studies are necessary to evaluated ethical and moral development of pharmacy students in a longitudinal fashion and on a larger scale. In particular, it would be interesting to note of an individual student's application of bioethical principles changes with didactic and clinical experience. This could even be expanded to follow them into professional practice.

\section{CONCLUSIONS}

To develop skills in handling ethical dilemmas, pharmacy students participate in a didactic ethics course and experiential rotations, providing opportunities to interact with the pharmacy environment and with common ethical dilemmas. Yet, in the present study, differences were noted between which bioethical principles are utilized by pharmacy students and pharmacists when handling ethical dilemmas. Students relied more on the principles of patient autonomy and nonmaleficience, while pharmacists also considered pharmacist autonomy. This suggests that students made decisions focused on patient rights, either based on their own moral code or the ethics code of the profession, while pharmacists also added legally conservative considerations. Although the students' views were in-line with the covenantal relationship stressed in the Pharmacist's Code of Ethics, schools of pharmacy and the pharmacy profession may need to provide students with more intentional exposure to ethical dilemmas so legal considerations are also factored into decisionmaking to ensure students are prepared to face such dilemmas in clinical practice.

\section{CONFLICT OF INTEREST}

Dr Schlesselman and members of her immediate family have no conflicts of interest or financial interests in any product or service discussed in the manuscript, including grants - pending or received -, employment, gifts, stock holdings or options, honoraria, consultancies, expert testimony, patents, and royalties

No funding was provided for this project.

\section{ESTUDIO TRANSVERSAL DE RAZONAMIENTO BIOÉTICO APLICADO EN ESTUDIANTES DE FARMACIA Y TUTORES}

\section{RESUMEN}

Objetivo: Compararlos principios éticos más comúnmente utilizados por los estudiantes de farmacia y los tutores para determinar el plan de acción ante un dilema ético, y determinar si los principios éticos utilizados son los mismos para individuos en fase postconvencional.

Método: Un cuestionario en dos partes se administró a una muestra de conveniencia de estudiantes de farmacia y tutores. La primera parte estaba formada por una medida original, el Pharmacy Ethical Dilemmas Survey (PEDS), que se desarrolló para evaluar la elección de acciones de los participantes sobre dilemas éticos relacionaos con la salud y cuáles eran sus reglas morales o principios éticos más influyentes en sus decisiones. La segunda parte estaba formada por el Defining Issues Test. Resultados: La autonomía del paciente y la no maleficencia eran los principios bioéticos aplicados por los estudiantes, pero los farmacéuticos aplicaban la no maleficencia, la autonomía del paciente, pero también la autonomía del farmacéutico. En todos los escenarios los estudiantes confiaban más en el principio de beneficencia, mientras que los tutores tenían más probabilidad de confiar en el derecho de autonomía del farmacéutico. En el análisis de la aplicación de los principios bioéticos por los individuos con más y con menos razona miento basado en principios, sólo en el escenario del suicidio asistido los dos grupos estuvieron de acuerdo en que el principio más importante a ser aplicado era el de autonomía del paciente.

Conclusión: Los estudiantes y los tutores utilizan diferentes principios bioéticos para apoyar el manejo de dilemas éticos, pero las puntuaciones $\mathrm{P}$ no determinan que principios bioéticos fueron usados en su selección de acciones.

Palabras clave: Ética Farmacéutica; Ética Basada en Principios; Práctica Profesional; Actitud del Personal de Salud; Estados Unidos

\section{References}

1. Sporrong SK, Hoglund AT, Arnetz B. Measuring moral distress in pharmacy and clinical practice. Nurs Ethics. 2006;13(4):416-427.

2. Rest JR. Moral development: Advances in research and theory. Santa Barbara: Praeger Publishing; 1986.

3. Rest JR, Narvaez D, Bebeau M, Thoma S. A neo-Kohlbergian approach: the DIT and schema theory. Educ Psychol Rev. 1999;11(4):291-324.

4. Kohlberg L. Stages of moral development as a basis for moral education. In: Beck C, Sullivan E (Eds.), Moral education. Toronto: University of Toronto Press; 1970.

5. Piaget J. The moral development of the child. New York: Free Press; 1932

6. Latif DA. Ethical cognition and selection-socialization in retail pharmacy. J Bus Ethics. 2000;25(4):343-357.

7. Rest JR, Narvaez D. Moral development in the professions: Psychology and applied ethics. Hillsdale, NJ: Lawrence Eribaum; 1994

8. Beauchamp T, Childress J. Principles of biomedical ethics (5th ed.). Oxford: Oxford University Press; 2001.

9. Elwell RJ, Bailie GR. Influence of classroom and clinical experience on the ethical decisions made by doctor of pharmacy students. The International Journal of Pharmacy Education 2003: 1(1)

10. Latif DA. An assessment of the ethical reasoning of United States pharmacy students: A national study. Am J Pharm Educ. 2004;68(2):30. 
11. Lowenthal W, Klein WS, Overton CP. Thinking about ethical dilemmas in pharmacy. Am J Pharm Educ. 1986;50:161164.

12. Cooper RJ, Bissell P, Wingfield J. Ethical decision-making, passivity and pharmacy. J Med Ethics. 2008;34(6):441-445. doi: 10.1136/jme.2007.022624

13. Benson A, Cribb A, Barber N. Understanding pharmacists' values: A qualitative study of ideals and dilemmas in UK pharmacy practice. Soc Sci Med. 2009;68(12):2223-2230. doi: 10.1016/j.socscimed.2009.03.012

14. Hibbert D, Reese JA, Smith I. Ethical awareness of community pharmacists. Int J Pharm Pract. 2000;8(2):82-87.

15. Lowenthal W. Ethical dilemmas in pharmacy. J Med Ethics. 1988;14(1):31-34.

16. Kohlberg L. Stage and sequence: The cognitive-developmental approach to socialization. In: Puka B (Eds). Defining perspectives in moral development. New York, NY: Garland Publishing; 1994. 